INVESTIGACIÓN/RESEARCH

\title{
UN ESCAÑO EN FACEBOOK: POLÍTICA 2.0, MARKETING VIRAL Y REDES SOCIALES
}

Miguel Túñez-López: Universidad de Santiago de Compostela. España

miguel.tunez@usc.es

José Sixto-García1: Universidad de Santiago de Compostela. España jose.sixto@usc.es

\section{RESUMEN}

El crecimiento de las redes sociales en todo el mundo obliga a las organizaciones a tener presencia en la red para poder instituir y conservar relaciones estables con sus usuarios, intentando conseguir su lealtad y fidelidad, de forma que sean ellos mismos quienes recomienden sus productos a otros usuarios mediante técnicas y mecanismos de expansión viral. ¿Sucede lo mismo en política? La proactividad de los actores políticos, en ejemplos como la campaña del presidente Obama, o de los receptores, en los recientes sucesos en Egipto, revalidan los entramados de intercomunicación personal on line como un nuevo soporte de flujos informativos que demuestra la transformación de las formas clásicas de relación social. Este estudio busca los perfiles en Facebook de los 350 congresistas españoles para analizar su nivel de interactividad virtual y dibujar sus estrategias de posicionamiento y las dinámicas de uso de los nuevos escenarios de comunicación para la acción política en un entorno en el que se estima que diariamente usan 7,5 millones de usuarios activos en España.

PALABRAS CLAVE: Redes Sociales - Política 2.0 - Marketing viral - Interactividad One to one

\footnotetext{
1 Autor correspondiente:

José Sixto-García: Profesor en la Facultad de Ciencias de la Comunicación de la Universidad de Santiago de Compostela, España

Correo: jose.sixto@usc.es
} 


\title{
A SEAT IN FACEBOOK: POLITICS 2.0, VIRAL MARKETING AND SOCIAL NETWORKS
}

\begin{abstract}
The growth of social networks all over the world forces to the organisations to have presence in the network to be able to create and conserve stable relations with the users -trying achieving their loyalty and fidelity-, so that they recommend products to other users using technicians and mechanisms of viral expansion. What about in politics? The political actors' pro-activity, like the president Obama's campaign, or the receptors activity, such as in the recent events in Egypt, revalidate the on-line personal intercommunication like a new support of informative flows, showing the transformation of the classical forms of social relation. This study investigates the 350 Spanish congressmen' profiles in Facebook in order to analyze the level of virtual interactiveness, define the strategies of targeting and the dynamics of use of the new stage of communication for the political action in a field used by 7,5 million active users daily in Spain.
\end{abstract}

KEY WORDS: Social networks - Politics 2.0 - Viral marketing - Interactiveness - One to one

\section{INTRODUCCIÓN}

Uno de cada cuatro usuarios españoles que se conecta a Internet $(38,3 \%)$ accede a alguna red social, según los datos de la última oleada del Estudio General de Medios (octubre/noviembre 2010). La cifra solo es superada por otras tres acciones de uso de red: el correo electrónico $(88,6 \%)$, la consulta de noticias de actualidad $(53,7 \%)$ y los servicios de mensajería instantánea $(48,9 \%)$.

En la red se han ido creando formas propias de intercomunicarse y de relacionarse socialmente. Todos usan la red para enviar y recibir correos electrónicos pero las diferencias por grupos de edades son significativas: Los mayores acceden a internet a buscar información y documentación. Los más jóvenes van a la red para relacionarse, subir y descargar videos y juegos, imágenes y películas, según la Encuesta sobre equipamiento y uso de tecnologías de la información y comunicación en los hogares 2010 del INE. 
Tabla 1. Actividades frecuentes en Internet en los últimos 3 meses, por edades (en \%)

\begin{tabular}{|l|c|c|c|c|c|c|c|}
\hline ACTIVIDAD EN INTERNET & Total & $16-24$ & $25-34$ & $35-44$ & $45-54$ & $55-64$ & $65-74$ \\
\hline $\begin{array}{l}\text { Envío de mensajes a chats, } \\
\text { blogs, grupos de noticias oforos } \\
\text { de discusión on-line, uso de } \\
\text { mensajería instantánea }\end{array}$ & 48,9 & 78,8 & 58,6 & 40,7 & 29,1 & 22,0 & 18,2 \\
\hline $\begin{array}{l}\text { Jugar o descargar juegos, } \\
\text { imágenes, películas o música }\end{array}$ & 44,0 & 72,1 & 49,7 & 38,0 & 27,1 & $\mathbf{1 9 , 5}$ & 20,2 \\
\hline $\begin{array}{l}\text { Colgar contenidos propios } \\
\text { texto, imágenes, fotos, videos, } \\
\text { música, etc.) en una página web } \\
\text { para ser compartidos }\end{array}$ & 35,9 & $\mathbf{6 7 , 6}$ & $\mathbf{4 3 , 5}$ & 25 & $\mathbf{1 6 , 5}$ & $\mathbf{1 6 , 1}$ & $\mathbf{1 8 , 5}$ \\
\hline $\begin{array}{l}\text { Recibir o enviar correo } \\
\text { electrónico }\end{array}$ & $\mathbf{8 5 , 8}$ & $\mathbf{9 0 , 5}$ & $\mathbf{8 9 , 1}$ & $\mathbf{8 4 , 6}$ & $\mathbf{8 0 , 1}$ & $\mathbf{7 9 , 6}$ & $\mathbf{8 4 , 9}$ \\
\hline $\begin{array}{l}\text { Leer o descargar noticias, } \\
\text { periódicos o revistas de } \\
\text { actualidad on line }\end{array}$ & $\mathbf{6 2 , 0}$ & $\mathbf{5 4 , 4}$ & $\mathbf{6 3 , 5}$ & $\mathbf{6 4 , 8}$ & $\mathbf{6 1 , 9}$ & $\mathbf{6 6 , 5}$ & $\mathbf{6 1 , 9}$ \\
\hline
\end{tabular}

Fuente: Instituto Nacional de Estadística, 2010. Elaboración propia.

España es el cuarto país (después de Holanda, India y México) donde más clientes se consiguen a través de las redes sociales, según una encuesta de la operadora de espacios de trabajo Regus (2010). Mientras que un $27 \%$ de las de las empresas a nivel mundial dedica una parte de su presupuesto de marketing solo a actividades en las redes sociales, en España la cifra asciende hasta el 50\% de las empresas, que emplean las redes sociales como medio para obtener nuevos negocios, según la encuesta de Regus.

Las redes sociales en entornos virtuales están transformando los modos de intercomunicación personal y grupal tanto en acciones unidireccionales como en actos multidireccionales (todos con todos). La principal transformación no está solo en el modo de relacionarse, ni en el soporte virtual. El auténtico significado de esta transformación es que los flujos informativos se han democratizado y universalizado porque sin depender de nadie el individuo tiene la posibilidad de convertirse en emisor al disponer de internet como canal de global.

De todas las redes sociales, Facebook es que cuenta con más usuarios en todo el planeta, unos 600 millones. El país que más usuarios aporta es Estados Unidos, unos 149 millones de miembros activos de los que el 70\% revisa su perfil diariamente. En España existen 13 millones de usuarios activos, de los cuales el 58\% entra a la red a diario $^{2}$.

ComScore realizó a finales de 2010 un estudio de evaluación de las impresiones publicitarias en Estados Unidos en el que se constata que las impresiones de Facebook aumentaron un $22 \%$ con respecto a 2009 . De hecho, la red social ha sufragado la

${ }^{2}$ Son datos de la propia compañía (febrero, 2011). 
mejora general del mercado publicitario on line de gran manera, puesto que ha contribuido con cerca de 300.000 millones de anuncios por impresión, un 23\% del mercado, según datos de la propia compañía. Esto provoca que Facebook lidere el ranking de impresiones de publicidad en formatos Figuras en red y aunque los datos se refieren exclusivamente a Estados Unidos, su extrapolación a otros países es fácilmente asumible para deducir tendencias.

Como lugar de encuentro de audiencias astronómicas las redes se han convertido en un nuevo escenario de negocio y un nuevo circuito de flujo de mensajes comerciales que el marketing ha sabido incorporar a sus estrategias. Por sectores, son significativos los datos de las empresas consultoras: hasta un 63\% encuentra nuevos clientes a través de las redes sociales (la media mundial es del 40\%) y las empresas de tecnologías de la información y de las telecomunicaciones: hasta el 52\%.

Mantener el contacto con los miembros de la red, relacionarse con grupos de intereses comunes son actividades frecuentes en las redes sociales. Pero también lo es, con una incidencia que en España aún está por debajo de la media, usarlas para conectar, gestionar $\mathrm{u}$ organizar grupos de clientes. Es lógico deducir que la gestión de productos, ideas o servicios a través $\mathrm{d}$ redes sociales se puede enfocar con el objetivo de lograr el mayor número de contactos/usuarios posibles. Pero es lógico suponer, también, que no hay porque conformarse con contactos directos de promotor de la idea o el producto al usuario o destinatario, sino que se pueden ajustar las estrategias de comunicación que conviertan al receptor en un reemisor del mensaje de modo que la audiencia del mismo se multiplique.

El éxito de la pro-actividad el presidente estadounidense Barack Obama en su campaña electoral supuso el reconocimiento de la utilidad de los entornos virtuales y las redes sociales como escenario de acción política. Los recientes acontecimientos en el norte de África, y más concretamente lo acontecido en las revueltas populares de Egipto, han ratificado la fuerza de los nuevos escenarios y los nuevos flujos de comunicación en las redes de acción social en Internet. ¿Y en el día a día de la actividad política? ¿Han descubierto los políticos españoles las redes sociales como forma de conexión con el electorado? ¿Están en las redes? ¿Las usan como una forma de comunicación interpersonal con una actitud de dialogo interactivo o las entienden como otra acción masiva más y las emplean como un altavoz colectivo para pronunciar un discurso? 


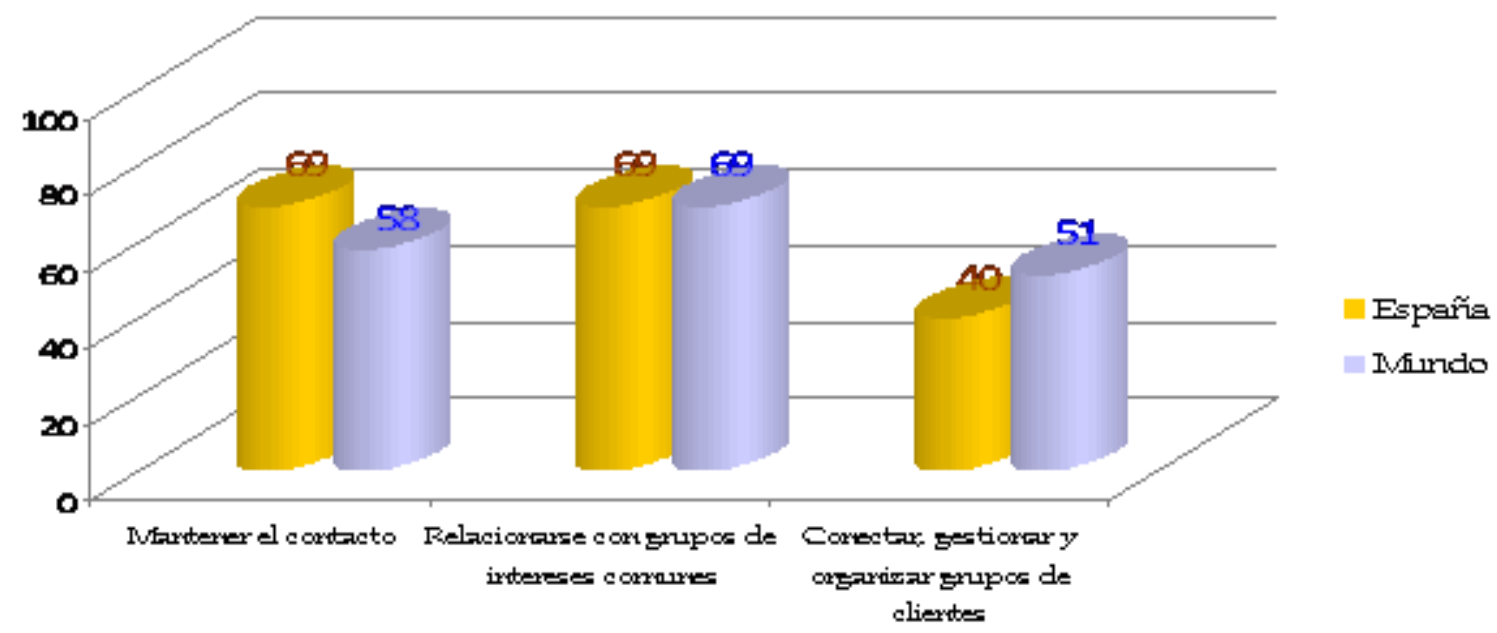

Figura 1. Usos de las redes sociales en España y en el mundo

Fuente: Regus y elaboración propia.

\section{METODOLOGÍA}

\subsection{Objetivos e hipótesis}

Comprobada la relevancia de Facebook como red social en todo el planeta y en España, nos planteamos unas primeras preguntas de investigación: ¿utilizan Facebook los diputados españoles para dar a conocer su actividad política o su imagen a través de Internet? ¿Qué estrategias usan para difundir sus campañas o actividades políticas? ¿Emplean técnicas de expansión y viralidad en red?.

Nuestra hipótesis de partida es que los diputados y diputadas españoles no don usuarios interactivos de las redes sociales y desaprovechan las potencialidades que ofrece Facebook para desarrollar campañas de marketing viral. En cualquier caso, formulamos cuatro objetivos por cumplir que nos permitiesen solventar las preguntas de investigación y corroborar o refutar la hipótesis de partida:

a) A partir de la contabilización de presencias de diputados y diputadas en Facebook, discernir entre perfiles abiertos y cerrados y dentro de ellos examinar cuáles presentan enlaces o links a otros sitios web para determinar el nivel de contagio viral entre fuente y recursos.

b) Comparar los datos anteriores con los vínculos oficiales para cuantificar presencias públicas en espacios virtuales 2.0 y medir la incidencia de la red social dentro de ese contorno genérico.

c) Profundizar en el tipo de contenido publicado en los perfiles desde el punto de vista informativo y desde la perspectiva de la privacidad, distinguiendo entre comunicación privada realizada para la red de contactos y comunicación pública, cerciorándonos a su vez en su grao de idoneidad para las esferas políticas. 
d) Valorar, interpretar y dotar de significado a los resultados objetivos obtenidos, de tal forma que podamos encontrar directrices de aplicación de mecanismos de marketing viral y estrategias de expansión fuente a usuario y usuario a usuario.

\subsection{Metodología desarrollada}

Este artículo referencia parte de los datos obtenidos a partir de una investigación más amplia relativa al uso de las redes sociales en el Congreso de los Diputados. Dicha investigación ha requerido la utilización de diversas y combinadas técnicas de indagación tanto de índole cuantitativa como cualitativa. No obstante, haremos constar en este caso las más relevantes para la obtención de los resultados que aquí presentamos.

En primer lugar, para el examen de las presencias de los congresistas españoles en Facebook se simuló la técnica de la observación participante, desde el punto de vista de usuario-investigador que buscó uno a uno los 350 miembros del Congreso (total del universo) para localizarlos en la red social. La búsqueda se realizó en tres ocasiones consecutivas para reducir el margen de error ${ }^{3}$. Se estudió el universo completo porque al ser tan reducido consideramos aconsejable optar por una muestra equivalente al universo a fin de minimizar distorsiones. En este caso, con $\mathrm{N}=350$, margen de error del $2 \%$ y un intervalo de confianza del $99 \%$ necesitábamos un (n) de 323 sujetos. Reducir el nivel de confianza al 95\% significaba trabajar con un tamaño de muestra de 306 diputados. Por ello, se decidió que $\mathrm{N}=(\mathrm{n})=350$.

Esta indagación se complementó con los datos oficiales publicados en la web del Congreso en cuanto a presencias oficiales de los diputados en la red. La intención de análisis fue de corte comparativo, tanto en el propósito de localizar posibles discrepancias con el examen de la observación participante como para poder ejecutar el posterior análisis comparativo entre lo real y lo oficial.

Para el análisis de contenidos se diseñó una ficha de indagación de opciones resolutorias cerradas, con la finalidad de evitar controversias interpretativas y agilizar la lectura de los resultados. Estos resultados fueron tratados en bases de datos efectuadas en Excel para la consecución de cruzamientos y también en SPSS PASW 18 Statistics para lograr resultados de significación estadística.

La interpretación de los datos, así como su valoración y explotación causal, se reforzó con el apoyo y la consulta bibliográfica de la discusión al respecto que formulan los expertos en la materia, especialmente en los campos del marketing, del marketing viral, de los mecanismos de contagio y de las técnicas de propagación y expansión.

\footnotetext{
${ }^{3}$ Las presencias con registro posterior al 30 de diciembre de 2010 no se han computado.
} 


\section{ANÁLISIS Y DISCUSIÓN}

El marketing de relaciones implica, en general, una orientación a largo plazo en el que todas las partes implicadas en el intercambio resultan beneficiadas. La relación con los usuarios resulta imprescindible, sobre todo ahora, cuando los mercados han adquirido una dimensión global en el espacio y atemporal en el tiempo, gracias al desarrollo de Internet en todo el planeta.

Las organizaciones, independientemente de su naturaleza (política, empresarial, sin ánimo de lucro, etc.), han de tomar conciencia de estos cambios para, en primer lugar, poder adaptarse a las necesidades de sus usuarios y, por otro lado, ser capaces de enfrentarse a la competencia de manera solvente. No solo se han modificado las relaciones entre los participantes en el proceso de intercambio, sino que también los productos incorporan y admiten cada vez más información, recursos, potencialidades y particularidades. La idea de la producción en masa dirigida a consumidores apelotonados decae día a día a favor de una producción orientada a la demanda particular del usuario individual.

Internet posibilita enormemente este tipo de relación individualizada y personalizada con un número casi infinito de usuarios, permitiendo la implantación del marketing one to one (uno a uno) (Peppers y Rogers, 2000), cuyas diferencias con respecto al marketing tradicional o de relaciones aisladas son patentes. Sin embargo, la historia del boca a boca es tan antigua como la propia humanidad (rumores, chismes de barrios y aldeas, historias que cantaban los pregoneros, etc.), pero la dimensión y la velocidad que adquiere gracias a las nuevas tecnologías son quienes, en efecto, permiten la aplicación del llamado marketing viral (Sivera, 2008).

\subsection{Estrategias a largo plazo y marketing de relaciones}

A medida que la filosofía y la práctica del marketing han ido evolucionando desde los comienzos de su aplicación a principios del siglo XX, cada vez se ha ido optando por concentrar los esfuerzos de la actividad en grupos lo más reducidos posible, hasta llegar al punto de personalizar la oferta (Peppers y Rogers, 2000), al tiempo que se constató que las relaciones suelen intensificarse a partir del primer contacto (Levitt, 1986, p. 115-117).

A partir de 1990, como consecuencia del reconocimiento expreso de las situaciones cambiantes de los mercados, el marketing de relaciones recibe especial atención y su importancia empieza a repercutir tanto en los mercados de consumo como en los industriales y tanto a nivel de usuario final como en las relaciones establecidas en el canal de distribución (Moliner y Callarisa, 1997). Entre las comunidades científica y empresarial se extiende la idea de que a medida que las relaciones se implementan y mantienen en el tiempo, los nexos y vínculos entre las partes que las ejecutan se 
estrechan, aumenta el nivel de confianza y ambas partes se muestran más predispuestas a ayudarse mutuamente ${ }^{4}$.

J. R. Nevin (1995) distingue cuatro perspectivas en la evolución del concepto, tal como recoge la siguiente figura:

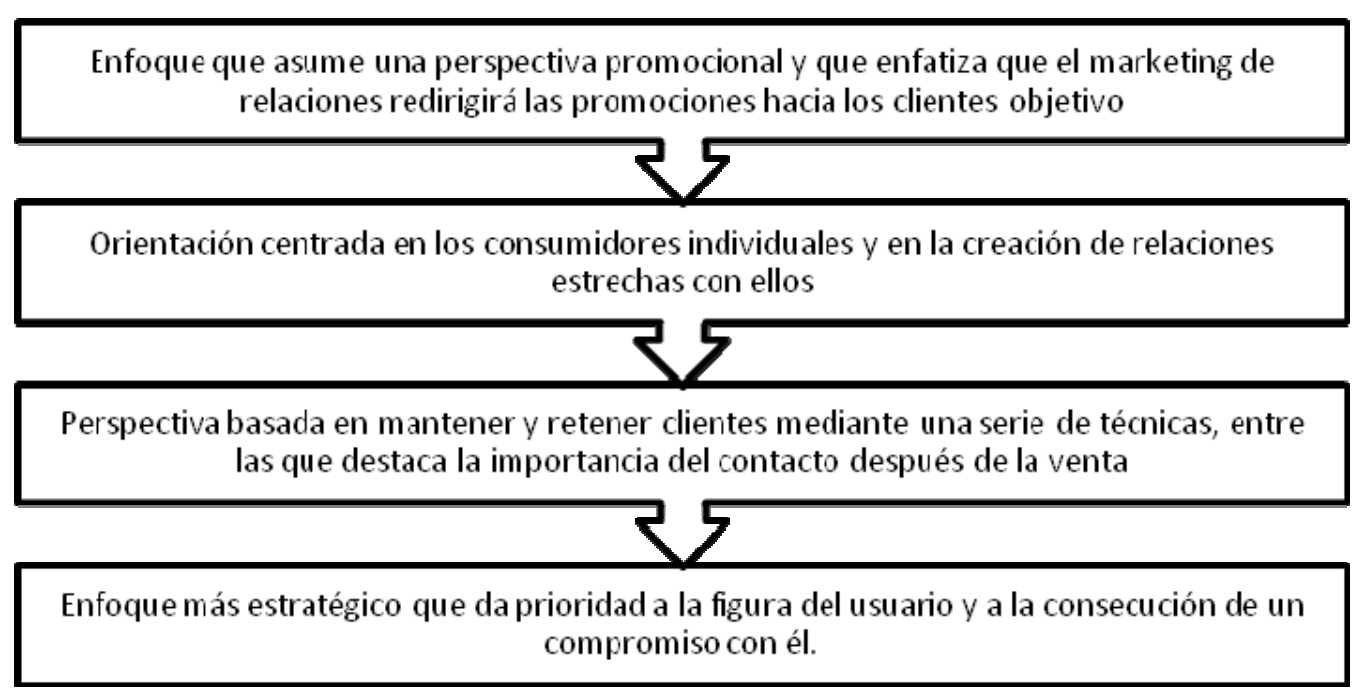

Figura 2. Evolución del ejercicio de relaciones

Fuente: Nevin (1995) y elaboración propia.

En este sentido, el marketing de relaciones concibe la cooperación mutua como la estrategia clave para la creación de un valor mayor ${ }^{5}$, mientras que la eliminación de la independencia de los diversos actores provoca un sistema económico más eficiente y la reducción en los grados de libertad de las partes implicadas puede conducir a una eficiencia mayor (Sheth \& Parvatiyar, 1999).

Así las cosas, son varios los factores que diferencian el marketing de relaciones del marketing de relaciones aisladas, aunque indudablemente es el establecimiento de relaciones a largo plazo lo que concede mayor importancia al valor y a la compatibilidad. S. K. Pinto (1997) atribuye cinco características determinantes del marketing relacional:

\footnotetext{
${ }^{4}$ Philip Kotler razona el concepto de marketing de relaciones a partir de la noción de intercambio, concepto básico sobre el que descansa el marketing, y concreta que su objetivo se fundamenta en "construir relaciones a largo plazo basadas en la confianza mutua con los clientes, distribuidores, comercios y suministradores más interesantes" (2003, p. 7).

${ }^{5} \mathrm{El}$ valor refleja la diferencia que obtiene el usuario al adquirir el producto y el gasto que le supone esa adquisición. Se trata de un elemento puramente subjetivo que es percibido en particular por cada uno de los usuarios, aunque para ellos "significa mucho más que la cantidad de dinero cobrada por el producto" (Stanton, Etzel e Walker, 2007, p. 13). Philip Kotler apunta, además, que "la expectativa de valor se puede definir como la diferencia entre los valores positivos y negativos que se espera recibir" (2003, p. 6), de manera que no todos los usuarios coinciden en apreciar de la misma forma un mismo producto, lo que deriva en que cada uno de ellos configura una percepción subjetiva del valor de cada producto susceptible de satisfacer una necesidad específica.
} 


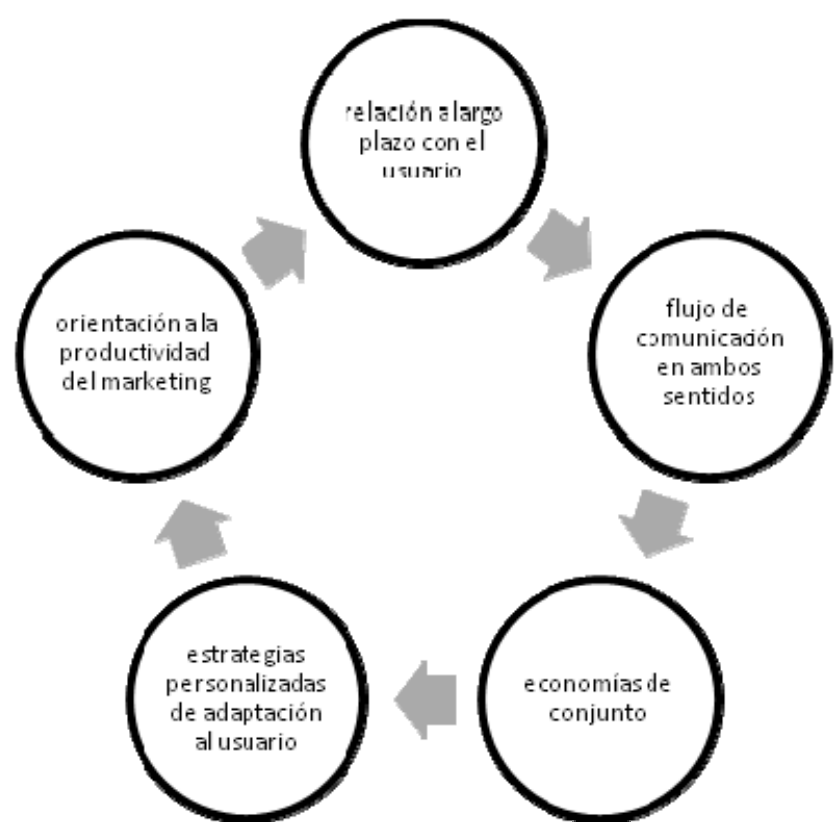

Figura 3. Características del marketing relacional Fuente: Pinto (1997) y elaboración propia.

\subsection{Relaciones que implican viralidad: marketing viral}

Anunciábamos antes que la utilización de Internet en el terreno de actuación del marketing reduce los costes, favorece el desarrollo de tiendas virtuales abiertas 24 horas y beneficia una distribución cada vez más rápida y garantizada ${ }^{6}$.

Si la comunicación entre los usuarios y las organizaciones ha aumentado, también el uso de la red como fuente informativa y soporte de comparación de opiniones de usuarios interesados en la oferta afecta indiscutiblemente a los productos:

a) El producto puede adaptarse a las necesidades específicas de cada usuario recopilando información sobre el perfil de cada consumidor en las redes sociales.

b) Es viable ofertar la posibilidad de cada usuario configure su propio producto.

c) Muchos productos han dejado de existir en soporte material y su existencia es exclusivamente virtual.

Por todo ello, aseguran R. Blattberg y J. Deighton (1991) que el marketing de relaciones ${ }^{7}$ supone un regreso al pasado, pero usando las tecnologías actuales. Se trata de un enfoque conservador ${ }^{8}$ de las relaciones de intercambio con el mercado, intentando emular la figura del viejo comerciante que conocía personalmente a su clientela y sabía cuáles eran sus gustos, y a la vez un enfoque realista por su vocación

\footnotetext{
${ }^{6}$ Uno de los sistemas más utilizados consiste en la desintermediación, es decir, en la venta al usuario final sin recurrir a los canales de distribución habituales, que, además, permite conseguir información de primera mano de los usuarios.

${ }^{7}$ También se denomina marketing interactivo.

${ }^{8}$ Enfoque "retro" en el original.
} 
de mantener a los usuarios actuales en lugar de procurar otros nuevos (Santesmases, 2007, p. 77 y ss.). Su filosofía, por tanto, radica más en mantener lo que hay que en intentar hacer maravillas con usuarios nuevos y desconocidos, consiguiendo más y mejor rentabilidad con los usuarios actuales. El refranero español define perfectamente la práctica de este marketing cuando recoge que vale más pájaro en mano que ciento volando.

En este contexto global que describe un aumento de la competencia y el consecuente incremento de las exigencias de quien adquiere o consume, unido a una liberación generaliza de los mercados, el marketing viral se erige como una de las técnicas primordiales del marketing de relaciones, donde las estrategias se planifican y ejecutan a largo plazo, dando prioridad a los usuarios del presente, dotando a los productos del mayor valor posible y consolidando la fortaleza de la organización frente al resto de la competencia.

D. Rushkoff, profesor de Cultura Viral en la Universidad de Nueva York, publicó en Media Virus (1996) las bases de lo que hoy llamamos marketing viral. Su hipótesis de partida apuntaba a que si un mensaje con unas características concretas llega a un usuario interesado, este se infectará de ese mensaje y estará preparado para seguir infectando a otros usuarios sensibles que a su vez transmitirán el virus de modo exponencial.

En la práctica, la primera experiencia sólida de implementación de estrategias de marketing viral se produjo con el lanzamiento al mercado de Hotmail también en 1996. Fueron los propios usuarios quienes recomendaban la marca al enviar sus correos electrónicos con la posdata "Consigue tu correo electrónico gratuito con Hotmail". Alcanzaron 12 millones de usuarios en 18 meses (Sivera, 2008).

El marketing viral consiste, pues, en la difusión rápida y masiva de un mensaje a través de Internet. Su eficacia radica en el atractivo de una determinada página web, de un perfil en una red social o de un correo electrónico que una organización ${ }^{9}$ envía a unos destinatarios concretos. Por eso, la red se está usando para practicar técnicas y estrategias de marketing relacional que permitan crear comunidades o grupos de usuarios afines a una marca o a un producto. En muchos casos son los propios usuarios quienes dan a conocer ese producto o servicio a través de Internet (Gómez y Veloso, 2002), de manera que estos lugares web constituyen un auténtico punto de encuentro en el que se comparten opiniones, se debaten características de los productos o simplemente se señala con un "me gusta" la correspondencia con lo que el sitio web difunde.

Al tratarse de un mercado hiperconectado a cada usuario se le brinda la posibilidad de aprender de toda una comunidad de consumidores implicados, lo que les permite reducir los riesgos de adquisición, consumo o servicio $\mathrm{y}$, por tanto, desde la

\footnotetext{
${ }^{9}$ Cuando hablamos de organización no nos referimos a personas jurídicas exclusivamente, sino también
} a personas físicas. 
perspectiva de las organizaciones también a ellas se les menguan las opciones de engaño, falsa publicidad y monopolio.

Así pues, el engranaje que mueve los procesos virales se articula en función de dos poleas:

a) El establecimiento, la consolidación y el mantenimiento de relaciones sólidas entre los usuarios que favorecen el intercambio de contenidos creados por ellos mismos o creados por terceros pero de los que ellos promueven su difusión.

b) La expansión y difusión de esos materiales utilizando técnicas de contagio y esparcimiento.

Es por ello que las estrategias cimentadas en la filosofía del marketing viral pretenden lograr que el usuario se convierta en visitante asiduo de la web o del perfil social, intentando, además, que quede tan satisfecho que recomiende el sitio o los productos en él ofertados a la red de contactos con los que mantiene relaciones habituales.

El tipo de interactividad ofrecida por Internet (Sterne, 1999; Timmers, 2000) se convierte en la principal causa por la que el usuario alcanza el grado máximo de implicación con la actividad que ejecuta (navegación por espacios web) ${ }^{10}$. Si a ello le añadimos un mayor conocimiento del perfil o de las características individuales de cada usuario (one to one) y una retroalimentación inmediata el resultado tiende a ser fantástico.

Confirmado que en una situación competitiva en la que los usuarios/consumidores pueden escoger entre muchas alternativas conseguir su fidelidad y lealtad no es sencillo, Santesmases (2007) considera que la calidad del producto no es suficiente y que la solución apuesta por desarrollar un marketing que integre al usuario en la organización, para crear una relación permanente entre ambos y que sirva de referencia para la captación de nuevos clientes.

En consecuencia, el marketing viral explota las redes sociales preexistentes para producir incrementos exponenciales en conocimiento del producto o de la marca mediante procesos de autorreplicación viral análogos a la expansión de un virus informático ${ }^{11}$. Por lo tanto, aunque se basa en la técnica del boca a boca ${ }^{12}$, el marketing viral es el tipo de virus más joven.

\footnotetext{
${ }^{10}$ La navegación en la red puede entenderse como el proceso de movimiento autodirigido a través de un entorno computerizado hipermedia que proporciona al usuario libertad y control de elección ilimitados en comparación con soportes más tradicionales y restrictivos (Hoffman y Novak, 1996).

${ }^{11}$ En un estudio comparativo Boase y Wellman (2001) distinguieron entre virus biológicos, informáticos y de marketing (viral) aportando datos relevantes para entender los mecanismos que tienen en común y cuáles los diferencian. En principio, todos estos virus dependen de redes para poder difundirse y la estructura de la red afecta a su distribución de manera similar, de modo que el contacto frecuente aumenta la posibilidad de contagio. Sin embargo, a diferencia de los primeros, normalmente los virus de marketing se acogen con agrado porque proporcionan información o, cuando menos, una
} 
No obstante, el elemento cultural del marketing viral es diferente con respecto al intercambio viral biológico e informático (casi siempre molestos e incómodos), ya que solo en el ámbito específico del marketing la replicación del virus tendrá lugar si coincide con la construcción cultural de algo que vale la pena compartir con otros (Sivera, 2008). No olvidemos que los virus -del latín virus, veneno- son entidades biológicas en la frontera entre la materia inanimada y la materia viva.

La expansión o difusión puede producirse mediante vínculos fuertes y consolidados por ejemplo, los contactos frecuentes y seguros de una red social- o mediante vínculos más débiles y que ofrecen menor confianza -como una frase incluida al final de un correo electrónico-.

En el caso de los contenidos que los usuarios crean mediante su participación en blogs, formatos de microblogging, redes sociales $u$ otros escenarios propios de la web $2.0 \mathrm{o}$ de la web interactiva, la expansión se efectúa mediante estrategias y prácticas que responden a concepciones del marketing relacional viral. Primero se crea, luego se comparte, o simplemente se comparte con la red de contactos del usuario lo que otros han creado.

Con la web 2.0 ha cambiado el esquema entre clientes y organizaciones; ahora los usuarios reaccionan y tienen voz propia. Youtube o Flickr constituyen ejemplos de sitios que apenas han invertido en publicidad y que se han convertido en populares en todo el mundo gracias al boca a boca.

\subsection{Modalidades afines}

Paralelamente al desarrollo del marketing viral han ido surgiendo otros términos de acuñación reciente próximos y afines. La profesora Silvia Sivera (2008) relaciona los siguientes:

a) Marketing influyente: trata de identificar e implicar a los consumidores más influyentes de un mercado determinado para convertirlos en incondicionales y recomendadores de la marca.

b) Marketing evangelista: trata de involucrar a los clientes más leales para convertirlos en incondicionales y recomendadores de la marca.

c) Street marketing: persigue alcanzar e interactuar con los usuarios directamente en sitios que frecuentan offline ${ }^{13}$.

d) Marketing encubierto: actúa bajo el umbral del conocimiento y el consumidor no es consciente de estar involucrado en una acción comercial.

oportunidad de estar al tanto de las modas, proporcionando al receptor la satisfacción de sentirse socialmente integrado.

${ }^{12}$ En una encuesta realizada por la consultora CIA:MediaEdge a 10.000 consumidores en el Reino Unido (2004), tres de cada cuatro encuestados $(76 \%)$ declaró que el boca a oreja era su principal influencia en las decisiones de compra, frente a un $15 \%$ que citó a la publicidad tradicional.

${ }^{13}$ Las acciones concretas enmarcadas en esta estrategia se denominan publicidad de guerrilla. 
e) Rumor marketing: implica que puede ser creado por la competencia o por un desconocido y afectar negativamente a la organización. En ese supuesto, debe efectuarse una acción neutralizadora para desmentir la información del rumor.

f) Blog marketing: consiste en el uso de weblogs para promover una marca o un producto. La gran ventaja de este tipo de marketing reside en su alto potencial viral: el contenido puede difundirse rápidamente e infectar la web porque otros usuarios recogen sus opiniones y algunos incluso reciben alertas gracias a la tecnología de sindicación de contenidos RSS.

g) Moblogging: es una variante del blog marketing pero basada en blogs vía teléfonos móviles.

\subsection{Resultados: política 2.0 y marketing viral}

Las redes sociales constituyen un escenario excelente para la ejecución de estrategias a largo plazo que supongan relaciones estables entre las fuentes y los usuarios a través, entre otras, de estrategias de marketing viral. ¿Pero también en la política?

Desde un perfil en una red social se distinguen dos modalidades diferenciadas de practicar este tipo de marketing:

a) En primer lugar, mediante los enlaces o links que se publican en el perfil y que dan acceso a otros lugares web que son de interés para el gestor del espacio.

b) Pero también mediante los muros abiertos o libres que ofrecen la opción de que los contactos de red publiquen sin censura en los perfiles. En esta segunda variante, las posibilidades de expansión y contagio son mayores, puesto que no solo es el gestor del espacio quien tiene potestad para publicitar otros sitios web, sino que los propios usuarios encuentran un espacio abierto y público en el que dar visibilidad a otros espacios que son de su interés. El factor de impacto crece de forma exponencial si se trata de perfiles o páginas de personas públicas con un número elevado de amigos o seguidores, como es el caso de algunos dirigentes políticos.

Testadas las aportaciones anteriores, nos preguntamos cuál sería el nivel de desarrollo e incidencia del marketing viral en los espacios en Facebook de los diputados y diputadas españoles.

La página web oficial del Congreso solo da enlace a página personal de 97 diputados, uno de cada cuatro $(27,71 \%)$. De ellos, la mayor actividad se concentra en la blogosfera (22,28\% del total de diputados, que representan el $80,41 \%$ de los que tienen página propia). Solo un tercio de los diputados con enlace propio desde la web del Congreso $(31,96 \%)$ referencian actividad en alguna red social, lo que proyectado sobre el conjunto del hemiciclo significa únicamente un $8,58 \%$ de diputados que publican una forma de contacto con ellos a través de las redes sociales. 
Tabla 2. Tipo de enlaces oficiales desde la web del Congreso

\begin{tabular}{|l|c|c|c|}
\hline \multirow{2}{*}{\multicolumn{1}{c|}{ Enlaces desde la web del Congreso }} & \multicolumn{3}{c|}{ Diputados y diputadas } \\
\cline { 2 - 4 } & $\mathrm{N}^{\mathrm{N}}$ & $\begin{array}{c}\% \\
\text { Total diputados del } \\
\text { Congreso (350) }\end{array}$ & $\begin{array}{c}\text { Diputados con } \\
\text { páginas } \\
\text { personales (97) }\end{array}$ \\
\hline Nada & 253 & 72,28 & 100 \\
\hline Páginas personales (en la web del Congreso) & 97 & 27,71 & 31,96 \\
\hline Enlace a alguna red social & 31 & 8,58 & 12,37 \\
\hline Web propia & 12 & 3,43 & 80,41 \\
\hline Blog & 78 & 22,28 & 13,4 \\
\hline Facebook & 13 & 3,71 & 12,37 \\
\hline Twitter & 12 & 3,43 & 8,25 \\
\hline GFC & 8 & 2,28 & 8,25 \\
\hline Flickr & 8 & 2,28 & 5,15 \\
\hline Youtube & 5 & 1,43 & 1,03 \\
\hline LikedIn & 1 & 0,28 & 9,28 \\
\hline Mail destacado & 9 & 2,57 & 9,28 \\
\hline Otros enlaces & 9 & 2,57 & \\
\hline
\end{tabular}

Fuente: elaboración propia

Son muchos más los que tiene perfil y actividad en las redes sociales que los que la declaran en su espacio oficial del Congreso. Desde la página web del Congreso solo 13 diputados dan enlace a su perfil o página en Facebook (3,71\% del hemiciclo y 13,4\% de los que tienen página propia en la web oficial de la Cámara). Nuestra investigación sobre los 350 congresistas nos ha permitido verificar 88 presencias oficiales de diputados en Facebook (25,14\% de los diputados/as).

El dato de partida es abrumador. Por una parte, significa desinterés por las redes sociales y por sus potencialidades de comunicación directa y control del mensaje. Por otra, supone un obstáculo comunicativo la actitud de los diputados que a pesar de contar con cuenta en Facebook no incluyen el link en su enlace personal desde la web oficial del Congreso. Esta actitud podría interpretarse como una reserva para un uso privado de la red pero en algunos casos más que un uso estrictamente personal se da un síntoma de desidia porque la actividad en sus muros es claramente de contenido político. En una interpretación de intenciones, podríamos sintetizarlo en una conducta en estar por estar en la red social, sin hacerlo ni público ni oficial y esperando a que los usuarios los encuentren.

Después de realizar tres rastreos en el buscador de Facebook con los nombres de los 350 congresistas nos encontramos con que solo están registrados, como decíamos, uno de cada cuatro $(25,14 \%)$. La mayoría son hombres $(15,71 \%)$ pero al relativizar los datos sobre los totales de diputados y diputadas las presencias por género se equilibran: un $25 \%$ de los diputados y un $25,38 \%$ de las diputadas están en la red social más numerosa. Están uno de cada cuatro pero no todos son accesibles. Los diputados que 
tienen abierta su información y su muro a cualquier usuario solo representan el 16,28\% del hemiciclo.

Tabla 3. Presencia de diputados/-as en Facebook

\begin{tabular}{|c|c|c|c|c|c|c|c|c|}
\hline \multirow{2}{*}{ Presencias en Facebook } & \multicolumn{2}{|c|}{$\begin{array}{c}\text { Congreso } \\
(350)\end{array}$} & \multicolumn{2}{|c|}{$\begin{array}{c}\text { Facebook } \\
\text { (88) }\end{array}$} & \multicolumn{2}{|c|}{$\begin{array}{c}\text { Diputados } \\
\text { (220) }\end{array}$} & \multicolumn{2}{|c|}{$\begin{array}{l}\text { Diputadas } \\
\text { (130) }\end{array}$} \\
\hline & $\mathrm{N}^{\mathrm{o}}$ & $\%$ & $\mathrm{~N}^{\mathrm{o}}$ & $\%$ & $\mathrm{~N}^{\mathrm{o}}$ & $\%$ & $\mathrm{~N}^{\mathrm{o}}$ & $\%$ \\
\hline Presencia en Facebook & 88 & 25,14 & 88 & 100 & \multirow{3}{*}{55} & \multirow{3}{*}{25} & \multirow{3}{*}{33} & \multirow{3}{*}{25,38} \\
\hline Hombres & 55 & 15,71 & 55 & 62,50 & & & & \\
\hline Mujeres & 33 & 9,42 & 33 & 37,50 & & & & \\
\hline Página/perfil & $89 *$ & 25,14 & 89 & 100 & 55 & 100 & 33 & 100 \\
\hline Página & 10 & 2,85 & 10 & 11,36 & 4 & 7,27 & 5 & 15,15 \\
\hline Perfil & 78 & 22,28 & 78 & 88,63 & 51 & 92,72 & 28 & 84,84 \\
\hline Página+perfil & 1 & 0,28 & 1 & 2,27 & 1 & 1,81 & 0 & 0 \\
\hline
\end{tabular}

Fuente: elaboración propia

Con relación al primer tipo de práctica que connota indicios de aplicación del marketing viral -enlazamientos a otros websites-, hallamos un 8,84\% de congresistas que publican algún tipo de vínculo o enlace a alguna web externa desde su perfil de Facebook. Se trata en la mayoría de los casos $(6,85 \%)$ de enlaces a webs personales que refuerzan su trayectoria personal y no la de grupo o partido. De hecho, solo el 1,14\% ofrece link a la web del partido político al que pertenece, lo que demuestra una priorización de los estrategias individuales frente a las grupales, es decir, un marketing enfocado más al político que a las ideas, una de premisa, por otra parte, que suele ser común en la implementación del marketing político, tanto en su vertiente tradicional como on line.

Si hacemos interpretación conforme a los diputados que poseen Facebook, los porcentajes ascienden porque los datos se proyectan sobre el conjunto de los 88 congresistas registrados en la red social. En cambio, lo que no varía de orden son las proporciones referentes a web personal, de partido o ambas, como puede comprobarse en el cuadro que sigue: 
Tabla 4. Enlaces a webs desde Facebook (localizados en buscador)

\begin{tabular}{|l|c|c|c|c|c|c|}
\hline \multirow{2}{*}{ Enlaces } & \multicolumn{3}{|c|}{ Congreso (350) } & \multicolumn{2}{c|}{ Facebook (88) } & \multicolumn{2}{c|}{ Perfiles abiertos (57) } \\
\cline { 2 - 7 } & $\mathbf{N}^{\mathbf{0}}$ & $\mathbf{0}$ & $\mathbf{N}^{\mathbf{0}}$ & $\mathbf{0}$ & $\mathbf{N}^{\mathbf{0}}$ & $\mathbf{\%}$ \\
\hline Enlace web personal & 24 & 6,85 & 24 & 27,27 & 22 & 38,59 \\
\hline Web partido & 4 & 1,14 & 4 & 4,54 & 3 & 5,26 \\
\hline + de 1 web & 3 & 0,85 & 3 & 3,4 & 2 & 3,5 \\
\hline Mail personal & 8 & 2,28 & 8 & 9,09 & 3 & 5,26 \\
\hline Mail partido/congreso & 2 & 0,57 & 2 & 2,27 & 2 & 3,5 \\
\hline Mail Congreso & 1 & 0,28 & 1 & 1,13 & 1 & 1,75 \\
\hline + de 1 mail & 2 & 0,57 & 2 & 2,27 & 2 & 3,5 \\
\hline
\end{tabular}

Fuente: Elaboración propia

Si en lugar de centrarnos en el sondeo exploratorio de búsqueda de los 350 diputados en Facebook, nos referimos en exclusiva a los enlaces oficiales desde la web del Congreso, las cifras son mucho menos confortadoras, ya que del total de diputados tres cuartas partes $(72,28 \%)$ no vincula ningún sitio web, lo que pone de manifiesto la desatención hacia las estrategias que denotan viralidad, hacia la navegación web y hacia la oficialidad de plataformas y soportes digitales.

De hecho, solo el 8,58\% del Congreso autoriza alguna red social en la página oficial, pero el $22,28 \%$ opta por los blogs, lo que significa un cierto estancamiento en la aceptación de las nuevas tecnologías 2.0, puesto que mientras que las redes sociales revolucionan el panorama comunicativo actual, los diputados continúan anclados en los blogs y solo el 3,43\% opta por microblogs (Twitter).

Con respecto a la segunda de las técnicas de marketing viral de aplicación plausible en los perfiles de Facebook - muros accesibles que ofrecen la opción de que los contactos de red publiquen en los perfiles-, encontramos un 16,28\% de muros abiertos sobre el total del Congreso (64,77\% sobre el conjunto de diputados con Facebook). Al referirnos al Congreso, la cifra es muy baja, pero lo positivo es que dentro de la minoría que decide registrarse en Facebook, seis de cada diez optar por hacerlo con muro de privacidad reducida o contenido público, de manera que los usuarios de red puedan acceder a sus publicaciones sin dificultades o trabas censoras.

En cuanto a la información que los diputados publican en su perfil, encontramos que es una práctica que realiza la mitad $(51,13 \%)$ de los diputados registrados, aunque si nos referimos al conjunto del Congreso la cifra es muy baja puesto que solo uno de cada diez diputados emplea esta estrategia $(12,85 \%)$, aunque, por otra parte, sea mayoritariamente utilizada $(70,17 \%)$ en los perfiles abiertos.

A pesar de que los datos son escasamente alentadores con respecto a la utilización de esta técnica viral, son peores si nos referimos al tipo de información que los congresistas proporcionan. En efecto, la mayoría de los perfiles $(28,40 \%)$ simplemente 
referencian información básica (un 7,14\% del Congreso). La red es básicamente comunicación interpersonal pero los diputados que dan información personal representan el 1,71\% del hemiciclo y el 6,88\% de los que tienen perfil o página en Facebook:

Tabla 5. Familia de información ofrecida en Facebook

\begin{tabular}{|l|c|c|c|c|c|c|}
\hline \multirow{2}{*}{} & \multicolumn{2}{|c|}{$\begin{array}{c}\text { Congreso } \\
\text { (350) }\end{array}$} & \multicolumn{2}{c|}{$\begin{array}{c}\text { Con presencia } \\
\text { en Fb (88) }\end{array}$} & \multicolumn{2}{c|}{$\begin{array}{c}\text { Con perfil abierto } \\
\text { (57) }\end{array}$} \\
\cline { 2 - 7 } & $\mathbf{N}^{\mathbf{0}}$ & $\mathbf{0}$ & $\mathbf{N}^{\mathbf{0}}$ & $\mathbf{\%}$ & $\mathbf{N}^{\mathbf{0}}$ & $\mathbf{\%}$ \\
\hline Ofrece información & 45 & 12,85 & 45 & 51,13 & 40 & 70,17 \\
\hline Información básica & 25 & 7,14 & 25 & 28,40 & 22 & 38,59 \\
\hline Información personal & 6 & 1,71 & 6 & 6,81 & 4 & 7,01 \\
\hline Información partido & 4 & 1,14 & 4 & 4,54 & 4 & 7,01 \\
\hline Información Congreso & 4 & 1,14 & 4 & 4,54 & 4 & 7,01 \\
\hline $\begin{array}{l}\text { Información } \\
\text { congreso/partido/personal }\end{array}$ & 6 & 1,71 & 6 & 6,81 & 6 & 10,52 \\
\hline
\end{tabular}

Fuente: Elaboración propia

Como señalábamos antes, los diputados apuestan por valorizar su acción individual frente a la de partido, aunque siempre desde la perspectiva de acciones o iniciativas políticas y/o parlamentarias. De hecho, el 32,9\% sobre el conjunto el total del Congreso realiza comunicación de tipo político y solo el 1,13\% opta por la de talante personal, aunque también es cierto que un $18,18 \%$ combina ambas.

La estrategia es de fácil comprensión: publicar contenido político para que los usuarios de Facebook puedan consumirlo frente a la táctica errónea de publicar para mí. Y también dejar que los demás publiquen, enlacen o comenten, fomentando el debate, la participación y erradicando la restricción a lo privado que no tiene sentido en la esfera política dentro de la red social.

No obstante, los niveles de interactividad logrados con los usuarios son insignificantes. En el muro responde el 14,07\% de los que tienen perfil abierto, mientras que en los foros el 3,5\%. De todos los que tienen Facebook el nivel de respuesta se sitúa en el 9,09\% y del total del Congreso en el 2,28\%. En foros las cifras descienden a $2,27 \%$ y $0,57 \%$ respectivamente. Son porcentajes minúsculos que se reducen todavía más al proyectar los datos sobre el conjunto de los diputados: las interacciones en redes sociales son una tarea que solo asume el 2,28\% de los miembros de la Cámara Baja.

De los recursos audiovisuales que permite la web 2.0 hacen un uso ínfimo. Solo el $11,36 \%$ se decanta por incorporar vídeos (todos de corte político y ninguno personal) en su espacio. En cuanto a las fotos su utilización es mayor $(31,81 \%)$, pero, por otra parte, es menor su capacidad discursiva. Su actualización se mueve entre los que emplean Facebook todos los días -incluso con varias aportaciones diarias- $(23,86 \%)$ y 
los que lo tienen pero no lo actualizan $(26,13 \%)$, lo que desvirtúa por completo la idiosincrasia del producto red social.

Por tanto, la apertura del muro no radica claramente en la calidad de la comunicación ni en la interactividad con los usuarios, de modo que constituye más un acto representativo que con efectos reales. De hecho, como demostramos arriba, escasean los muros abiertos en los que se produzca interacción real entre fuente y usuarios, permitiendo la expansión de los mensajes entre usuarios, la técnica de red a red o, en definitiva, el marketing viral.

\section{CONCLUSIONES}

Las redes sociales están promoviendo un nuevo escenario de comunicación que también afecta a los flujos de determinan como circula la información entre los individuos de una colectividad. La progresión casi geométrica del numero de usuarios convierte a las redes en lo que podríamos referir como las nuevas ágor@s virtuales del siglo XXI, y en nuevos foros de actividad política y en nuevos canales de difusión de discursos y todo tipo de mensajes, tanto políticos como comerciales, o de servicios, institucionales, promocionales, empresariales, o publicitarios.

A pesar de ese auge y del crecimiento como entorno de actividad empresarial no hay una utilización de las redes para la comunicación de los principales actores políticos (diputados y diputadas) y los ciudadanos. Los porcentajes de congresistas con perfil en las redes más numerosas en España son muy bajos: 3,.71\% en Facebook y 3,43\% en Twitter desde los espacios personales de la web oficial del Congreso; y 25,14\% en Facebook según los resultados de esta investigación.

Las cifras se reducen todavía más cuando se buscan presencias en la red social de diputados/as que permitan el acceso de cualquier ciudadano a la información de su perfil o a los contenidos que publican en su muros: solo $x x x$ de cada cien diputados/as $(12,85 \%)$.Es muy escasa la información personal. Se da la foto (más de campaña que de un entorno de comunicación interpersonal) pero no se ofrecen datos que humanicen al político en la Red.

El análisis del contenido de las publicaciones de los muros permite intuir que desarrollan una estrategia de promoción personal más que una acción de promoción de ideas o de organizaciones o partidos políticos.

Se da, en general, una actitud poco activa: son muchos más los que apuestan por publicar enlaces en los que se habla bien de sus iniciativas que aquellos que aportan contenidos propios. Apenas se combina la difusión de la acción política con las publicaciones que supongan aportaciones personales, en sintonía con la actividad de los usuarios con los que se interactúa en la Red.

Esta actitud indica que se conforman con estar en la red más que buscar la participación real. Su mensaje es más discurso que diálogo. Se desaprovecha el 
potencial de las redes sociales: ser uno más, aproximar el perfil, interrelacionarse con todos y buscar que el mensaje salte de muro en muro multiplicando el número de destinatarios a los que llega.

Se descuida el lenguaje coloquial, escasean las intervenciones afectivas (casi todos son razonamientos o argumentaciones intelectuales), apenas hay invocaciones a participar cerrando el post con alguna pregunta, las frecuencias de actualización de contenidos son irregulares y poco constantes, casi no hay vías alternativas de contacto (direcciones electrónicas o enlaces webs u otros hipervínculos) y es muy escaso el uso de recursos multimedia con apenas aportaciones de vídeo o audio propios.

Lejos de aproximarnos a la ciberdemocracia, no hay un uso generalizado de Facebook que anime a pensar en que se apuesta por las redes sociales como un escenario de actuación política diaria a pesar de que las audiencias de usuarios ya se cuentan por millones en España y las estimaciones de Facebook son que actualizan su perfil diariamente 7,5 millones de usuarios activos en España. No solo el 74,86\% no tiene perfil sino que la mayoría ni lo señala como enlace en su espacio personal en la página web oficial del Congreso (que sólo activaron uno de cada cuatro diputados, 72,28\%).

\section{REFERENCIAS}

Blattberg, R. \& Deighton, J. (1991). Interactive Marketing: Exploiting the Age of. Addressability, en Sloan Management Review, n 33, p. 5-14.

Boase, J. \& Wellman, B. (2001). A plague of Viruses: Biological, Computer and Marketing, en Current Sociology, no 49, p. 39-55.

Gómez, Á. \& Veloso, M. (2002). Marketing en Internet y en los Medios Digitales Interactivos. Santiago de Compostela: Escuela de Negocios Caixanova - Tórculo Edicións.

Hoffman, D. \& Novak, T. (1996). Marketing in hypermedia computer-mediated environments: conceptual foundations, en Journal of Marketing, vol. 60, p. 50-68.

Kotler, P. (2003). Los 80 conceptos esenciales de marketing. De la A a la Z. Madrid: Pearson.

INE (2010). Encuesta sobre equipamiento y uso de tecnologías de la información y comunicación en los hogares 2010, Consultado el 12 febrero de 2011, Disponible en: www.ine.es.

Levitt, T. (1986). Comercialización creativa. México: CECSA.

Moliner, M. A. \& Callarisa, L. J. (1997). El marketing relacional o la superación del paradigma transaccional, en Revista Europea de Dirección y Economía de la Empresa, 6, (2), p. $67-80$. 
Nevin, J. R. (1995). Relationship Marketing and Distribution Channels: Exploring Fundamental Issues, en Journal of the Academy of Marketing Science, 23, (4): 327-334.

Peppers, D. \& Rogers, M. (2000): Uno x Uno. El marketing del siglo XXI. Buenos Aires: Ediciones B Argentina.

Pinto, S. K. (1997). Marketing de relación o la transformación de la función de marketing, en Harvard Deusto Business Review: 32-40.

Rushkoff, D. (1996). Media Virus. Hidden agendas in popular culture. Nueva York: Ballantine Books.

Santesmases, M. (2007). Marketing. Conceptos y estrategias (5 $5^{\mathrm{a}}$ ed. revisada). Madrid: Pirámide.

Sheth, J. E. \& Parvatiyar, A. (1999). Handbook of Relationship Marketing. Thousand Oaks, C.A.: Sage Publications.

Sivera, S. (2008). Marketing viral. Barcelona: Editorial UOC.

Stanton, W. J., Etzel, M. J. \& Walker, B. J. (2008). Fundamentos de Marketing (14 ${ }^{\mathrm{a}}$ ed.). México D. F.: McGraw-Hill.

Sterne, J. (1999). World wide web Marketing, (2a ed. Londres): John Wiley \& Sons.

Timmers, P. (2000). Strategies and models for business-to-business trading electronic commerce. London: John Wiley \& Sons.

\section{José Miguel Túñez-López}

Profesor de Producción de la Información en la Universidad de Santiago de Compostela, España. Doctor en Periodismo por la Universidad Autónoma de Barcelona, España. Miembro del Grupo de Investigación Novos Medios, de la Universidad de Santiago de Compostela, España. Líneas de investigación: Newsmaking; Rutinas en la producción informativa; Gestión de la comunicación en las organizaciones; Condiciones laborales y Actitudes profesionales de los periodistas.

\section{José Sixto-García}

Profesor en la Facultad de Ciencias de la Comunicación de la Universidad de Santiago de Compostela, España. Entre sus líneas de investigación destacan la comunicación institucional/organizacional, el marketing y las Redes sociales. Recientemente ha publicado artículos como "Gabinetes que informan, medios que ratifican" o "Comportamientos activos en usuarios 2.0: Facebook supera a Tuenti, la Red social que había sido líder en España. Causas, estrategias de comunicación e impacto en la recepción". 